\title{
The free moment in walking and its change with foot rotation angle Sivan Almosnino ${ }^{\dagger 1,2}$, Tara Kajaks ${ }^{\dagger 3}$ and Patrick A Costigan* ${ }^{* 1,2}$
}

\begin{abstract}
Address: 'Biomechanics and Ergonomics Laboratory, School of Kinesiology and Health Studies, 69 Union St., Queen's University, Kingston, ON, K7L 3N6, Canada, ${ }^{2}$ Human Mobility Research Centre, Kingston General Hospital, 76 Stewart St., Kingston, ON, K7L 2V7, Canada and ${ }^{3}$ Biomechanics Laboratory, Department of Kinesiology, McMaster University, 1280 Main St. West, Hamilton, ON, L8S 4K1, Canada

Email: Sivan Almosnino - sivan.almosnino@queensu.ca; Tara Kajaks - kajakst@mcmaster.ca; Patrick A Costigan* - pat.costigan@queensu.ca

* Corresponding author †Equal contributors
\end{abstract}

Published: 13 August 2009

Sports Medicine, Arthroscopy, Rehabilitation, Therapy \& Technology 2009, I:19 doi:10.1186/1758-2555-I-19
Received: 17 March 2009

Accepted: 13 August 2009

This article is available from: http://www.smarttjournal.com/content/I/I/19

(C) 2009 Almosnino et al; licensee BioMed Central Ltd.

This is an Open Access article distributed under the terms of the Creative Commons Attribution License (http://creativecommons.org/licenses/by/2.0), which permits unrestricted use, distribution, and reproduction in any medium, provided the original work is properly cited.

\begin{abstract}
Background: This investigation characterized the time-history pattern of the free moment (FM) during walking and, additionally, assessed whether walking with either an internally or externally rotated foot position altered the FM's time-history.

Methods: Force plate and foot kinematic data were acquired simultaneously for II healthy subjects ( 6 males, 5 females) while walking at their self-selected comfortable speed in 3 foot rotation conditions (normal, internal and external). The FM was calculated and normalized by the product of each participant's body weight and height prior to extraction of peak FM, occurrence of peak FM in stance and net relative impulse. Differences in these values across foot rotation conditions were assessed using separate one-way, repeated measures analysis of variance and subsequent pair-wise comparisons.

Results: The average FM pattern during normal walking exhibits a biphasic shape: resisting inward rotation during approximately the first half of stance and outward rotation during the latter part of stance. While no differences in peak FM or net relative impulse were observed between the internal foot rotation condition and normal walking, the external foot rotation condition resulted in significantly greater peak FM and relative net impulse in comparison to normal walking.

Conclusion: The differences in selected FM variables between normal walking and the external foot rotation condition are attributable to individual subject response to walking with an externally rotated foot. In this condition, some subjects displayed a FM pattern that was similar to that recorded during normal walking, while others displayed markedly larger FM patterns that are comparable in magnitude to those reported for running. The larger FM values in these latter subjects are speculated to be a result of excessive transverse plane body movements. Whilst further investigation is warranted regarding the FM time-history characteristics during walking, our results indicate that the FM may provide useful information in assessment of gait.
\end{abstract}

\section{Background}

Ground reaction force (GRF) time-histories, measured predominantly using floor embedded force plates, have been documented extensively in both normal and patho- logical populations and for a variety of human ambulatory activities (e.g. [1-6]). The majority of investigations that quantify GRF patterns focus on forces acting along the primary, orthogonal axes (i.e. vertical, anterior-poste- 
rior and medio-lateral). An additional force plate measure rarely reported is the free moment (FM) (table 1). The FM is the reaction to the force couple exerted by the foot on the ground acting about a vertical axis originating at the foot's center of pressure $(\mathrm{CoP})$ (figure 1) $[7,8]$.

Recently, attention has been drawn to the clinical usefulness of the FM by Milner et al [9], who were able to discriminate retrospectively, based on FM indices, between a group of healthy runners and a group of female runners with a history of tibial stress fractures. Based on the results of Milner et al [9], it can be speculated that the FM might serve as an indicator for the amount of torsional loading experienced during ambulation. While this supposition has yet to be validated, there are two related points that make it appealing: one, cortical bone is not able to sustain large amounts of torsional loading [10,11], and, two, considerable torsional loading is experienced during ambulation, specifically during the push off phase of walking [12]. The question that naturally arises is whether an elevated FM during walking a potential cause of tibial stress fractures?

An elevated FM may be due to individual gait characteristics. Specifically, the FM has been found to be sensitive to gait modifications employed in the transverse plane: both Li et al [13] and Umberger [14] observed temporal and

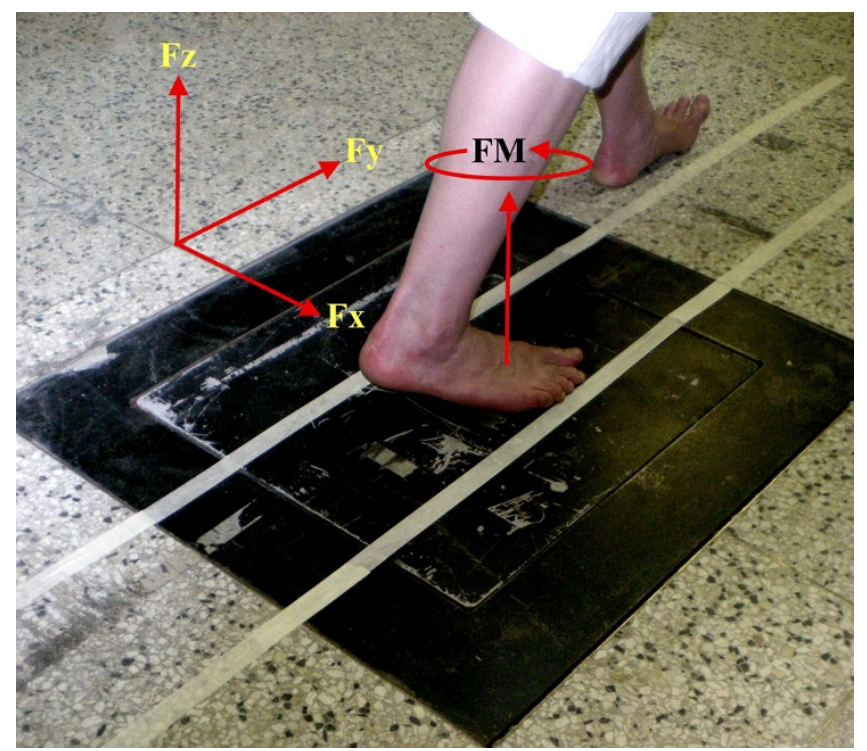

Figure I

Experimental procedures. White parallel lines placed over the walkway aided subjects in reproducing the foot rotation angle in the internal (INT) and external (EXT) conditions. The FM is depicted as acting vertically through the hypothetical location of the center of pressure at this time instant, and its direction is in accordance with the force plate coordinate system used in this investigation. amplitude dissimilarities in the FM pattern when subjects walked across a force platform with and without arm swing, a movement that exerts a transverse force couple on the ground during walking. The vertical and anteriorposterior GRF components, on the other hand, were virtually indistinguishable across the two arm conditions [14].

Another gait modification employed in the transverse plane, and that might influence the FM, is the foot rotation angle adopted during walking. Modification of the foot rotation angle during walking as been documented to occur naturally as a function of the goals of the ambulatory task, or may be artificially induced as part of an interventional program. For example, it has been suggested that the adaptation of an internally rotated foot position during walking minimizes the resistive moment that must be overcome by the ankle plantar flexors during the pushoff phase of stance [15]. This is achieved by effectively reducing the moment arm of the GRF vector with respect to the talocrural joint axis. Eredmir and Piazza [15] note that modifying the foot rotation angle to a more internal one has been observed in high school aged subjects during sprint-running [16], and in subjects walking while carrying external loads [17]. In contrast, several investigations have demonstrated that adapting a more externally rotated foot position decreases the magnitude of the knee adduction moment, thus unloading the medial compartment of the knee [18-21]. This is achieved by shortening the moment arm of the GRF in relation to the knee joint center in the frontal plane, primarily during the second half of stance [20]. While the influence of foot rotation on frontal knee and ankle moments has been examined, its influence on the transverse plane moments and the FM during walking has not been explored in adults.

While the influence of the foot rotation angle adopted during stance on the FM pattern is unclear, it can be postulated that, irrespective of the foot rotation position adopted relative to normal walking, attempting to align the foot with the direction of forward progress during late stance would require individuals to exert a twisting action of the foot on the ground that would subsequently alter the magnitude of the FM. Thus, the aim of this investigation is to test whether different foot rotation positions produce changes in the pattern of the FM pattern during walking. As part of this investigation, the pattern of the FM during normal walking will be described, consequently addressing the paucity of information related to this force plate measure.

\section{Methods}

This investigation used an existing data set [22], for which the data collection procedures have been outlined [2325]. These will be briefly described, as well as additional 
Table I: Investigations reporting upon the free moment (FM) during running and walking.

\begin{tabular}{|c|c|c|c|c|}
\hline Author(s), year & Activity & Subjects & $\begin{array}{c}\text { FM } \\
\text { Normalization }\end{array}$ & Peak FM ( \pm SD) † \\
\hline Nigg et al, $1982[34] \ddagger$ & Walking (w) \& Running (r) & 16, unilateral $A C L$ insufficiency & None & $\begin{array}{l}\text { (w) Injured limb I2.9 Nm } \\
\text { (w) Normal limb } 11.5 \mathrm{Nm} \\
\text { (r) Injured Limb 15.9 Nm } \\
\text { (r) Normal Limb I7.5 Nm }\end{array}$ \\
\hline Nigg, 1986 [7] § & $\begin{array}{l}\text { Running } \\
\left(3.5 \mathrm{~ms}^{-1}\right)\end{array}$ & I, rear foot striker. & None & $\begin{array}{l}\text { Range across different footwear } \\
\text { conditions 5-7 Nm }\end{array}$ \\
\hline $\begin{array}{l}\text { Holden \& Cavanagh, |99| } \\
\qquad[8] \epsilon\end{array}$ & $\begin{array}{c}\text { Running } \\
\left(4.5 \pm 10 \% \mathrm{~ms}^{-1}\right)\end{array}$ & I0, male, 'normal foot arches'. & $\mathrm{BW} \times \mathrm{ht}$ & $\begin{array}{l}\text { 'Varus' shoes } 6.7 \pm 1.6 \times 10^{-3} \\
\text { 'Neutral' shoes } 9.7 \pm 1.6 \times 10^{-3} \\
\text { 'Valgus' shoes } 12.4 \pm 1.6 \times 10^{-3}\end{array}$ \\
\hline Milner et al, 2006 [9] & $\begin{array}{c}\text { Running } \\
\left(3.7 \pm 5 \% \mathrm{~ms}^{-1}\right)\end{array}$ & $\begin{array}{c}\text { Control Group: } \\
\text { 25, mixed, healthy. } \\
\text { Experimental Group: } \\
\text { 25, female, history of tibial stress } \\
\text { fractures. }\end{array}$ & $B W \times h t$ & $\begin{array}{l}5.9 \pm 2.1 \times 10^{-3} \\
9.3 \pm 4.3 \times 10^{-3}\end{array}$ \\
\hline $\begin{array}{c}\text { Creaby \& Dixon, } 2008 \\
\text { [33] }\end{array}$ & $\begin{array}{c}\text { Running } \\
\left(3.6 \pm 5 \% \mathrm{~ms}^{-1}\right)\end{array}$ & $\begin{array}{c}\text { Control Group: } \\
20 \text { military recruits, no lower } \\
\text { extremity injuries. } \\
\text { Experimental Group: } \\
10 \text { military recruits, sustained } \\
\text { tibial stress fracture. }\end{array}$ & $\mathrm{BW} \times \mathrm{ht}$ & $\begin{array}{l}9.3 \pm 3.2 \times 10^{-3} \\
9.5 \pm 2.1 \times 10^{-3}\end{array}$ \\
\hline $\begin{array}{c}\text { Li et al, } \\
2001 \text { [13] }\end{array}$ & $\begin{array}{c}\text { Walking } \\
\text { ('low', 'comfortable', 'fast') }\end{array}$ & $\begin{array}{l}17 \text { total ( } 5 \text { adult males, } 6 \text { adult } \\
\text { females, } 6 \text { children). }\end{array}$ & BW & $\begin{array}{c}\text { Range across speed conditions, } \\
\text { adults only } \\
2.5-10.0 \times 10^{-3}\end{array}$ \\
\hline Umberger, $2008[14] \S$ & Walking $\left(1.3 \mathrm{~ms}^{-1}\right)$ & 5 male, 3 female, healthy. & $\mathrm{BW} \times \mathrm{LL}$ & $\begin{array}{c}\text { Range } \\
0.5-1.5 \times 10^{-2}\end{array}$ \\
\hline
\end{tabular}

$\mathrm{BW}=$ bodyweight, $\mathrm{ht}=$ height, $\mathrm{LL}=$ leg length

† Note differences in peak FM magnitude between studies due to different normalization procedures.

$\ddagger$ Nigg et al (1982) do not provide ambulation speeds, participant sex or peak FM dispersions measures.

$\notin$ Holden and Cavanagh (199I) report peak FM variability using the standard error of the mean (SEM).

Values were converted to SD by multiplying the SEM by the square root of the sample size $(n=10)$.

$\S$ Peak FM values not explicitly given. Approximate values are listed based on visual estimation of depicted FM time histories.

information pertaining to the aims of the current investigation.

\section{Subjects}

A convenience sample of six males (age (mean \pm SD) 23.9 \pm 1.8 years, height $1.84 \pm 0.07$ meters, weight $819 \pm 67 \mathrm{~N}$ ) and five females (age $21.9 \pm 0.8$ years, height $1.67 \pm 0.07$ meters, weight $579 \pm 63 \mathrm{~N}$ ) volunteered to participate in the study. None of the subjects were suffering from or reported a history of lower extremity injury. Prior to testing, all subjects were briefed on the procedures of the investigation and subsequently gave their informed consent. Approval for this study was obtained from the Queen's University's Research Ethics Board.

\section{Equipment}

Foot rotation angle during the stance phase, defined as the angle between the foot's long axis and the direction of forward progress, was calculated from the position of three active infrared-emitting diodes (IREDS) affixed directly to each subjects' right lateral malleoulus, tuber calcanei and $5^{\text {th }}$ metatarsal head. The IREDS were tracked in three dimensional space using two Optotrak position sensors (Northern Digital Inc., Waterloo, ON, Canada). Ground reaction force measurements were obtained using a straingauge force platform (model OR6-7-1000, AMTI Inc., Watertown, MA, USA). Both IRED and force plate data acquisition were sampled synchronously at $100 \mathrm{~Hz}$. A calibration procedure was employed prior to data collection to align the coordinate systems of the force plate and Optotrak system.

\section{Procedures}

Subsequent to marker placement, a static-standing calibration trial was performed with the subjects standing such that the middle-posterior aspect of the heel and $2^{\text {nd }}$ toe were aligned with the anterior-posterior force plate axis. All subsequent foot rotation angles are referenced to 
this position in the global coordinate system. Subjects were then asked to perform several practice trials while walking across the force platform at a self-selected comfortable speed. During these practice trials the normal (NORM) foot rotation angle of each of the subjects' right foot was determined. During testing, the subjects walked across the force platform normally (NORM) or while rotating their foot externally (EXT) or internally (INT) by approximately 30 degrees with respect to their NORM angle. To aid the subjects in reproducing the EXT and INT foot rotation angles during testing, two parallel lines were placed on the walkway (Figure 1). The gap between the two lines corresponded to each participant's individual foot length such that, when subjects walked with their foot filling the gap, the same foot rotation angle could be achieved. Subjects were given as many practice trials as needed in order to ensure their ability to walk comfortably while performing the INT and EXT conditions. The subjects performed five trials in each foot rotation condition (NORM, INT, EXT) in a random order. Arm swing was standardized across subjects and conditions by asking subjects to walk with their elbows bent at a 90 degree angle.

\section{Data Analysis}

Prior to the extraction of the variables of interest, kinematic data were filtered using a $2^{\text {nd }}$ order, zero phase shift, low pass Butterworth filter with a cut-off frequency of 6 $\mathrm{Hz}$. Calculation of the free moment was in accordance with a reaction-oriented, orthogonal force plate coordinate system, where the anterior-posterior axis $(Y)$ points in the direction of forward progression, the vertical axis $(Z)$ points upwards and the medio-lateral $(X)$ axis points to the right (Figure 1). Thus, with respect to the right foot, a positive free moment opposes outward rotation. Conversely, a negative free moment opposes inward rotation. The calculation of the FM requires the force $(F x, F y, F z)$ and moment $(M x, M y, M z)$ components, as well as the location of the CoP, which was calculated as follows:

$$
\begin{gathered}
C o P_{x}=-\frac{M_{y}+F_{x}\left(Z_{o f f}\right)}{F_{z}} \\
\operatorname{CoP}_{y}=\frac{M_{x}-F_{y}\left(Z_{o f f}\right)}{F_{z}}
\end{gathered}
$$

Where $\mathrm{CoP}_{x}$ and $\mathrm{CoP}_{y}$ are the positions of the center of pressure along the medio-lateral and anterior-posterior force plate axes, respectively, and $Z_{\text {off }}$ is the vertical distance offset between the surface and true center of the force plate. To control for erroneous $\mathrm{CoP}$ values at the beginning and end of stance due to division by small vertical forces $(F z)$, the calculation of the $\mathrm{CoP}$ was initiated and terminated when the $F z$ value was above $5 \%$ of the maximal value recorded during each trial. The FM is given by [26-28]:

$$
F M=M_{z}-F_{y}\left(\operatorname{CoP}_{x}\right)+F_{x}\left(\operatorname{CoP}_{y}\right)
$$

Note that the CoP and FM calculations are only valid for the model of force plate used in this investigation.

All FM waveforms were amplitude-normalized to the product of each individual's body weight $(\mathrm{N})$ and height (m). Additionally, the period of foot contact with the force plate was normalized to a uniform length of 101 data points, which represented $0 \quad 100 \%$ of the stance phase. To assess differences in FM between foot rotation conditions, the following dependent variables were extracted from each of the five trials performed in each condition and subsequently averaged per subject: peak free moment (PFM), occurrence of peak free moment in stance (OPFM) and the relative net impulse (IMP), which is the net area under the FM stance curve [29]. We also report the un-normalized peak FM magnitudes for comparison with studies that have chosen not to normalize the FM.

\section{Statistical Analysis}

Temporal similarity between pairs of FM waveforms (NORM vs. EXT and NORM vs. INT, respectively) was assessed using Pearson product moment correlation coefficient $(r)[30,31]$, while differences in magnitude were assessed by the root mean square difference (RMSD). RMSD values were calculated separately for each subject and subsequently averaged across subjects [14]. With regards to the calculation of $r$, since correlation coefficients are not normally distributed, a Fisher $\mathrm{Z}$ transformation was applied to all individual $r$ values, which were then averaged across subjects. Thereafter, the hyperbolic tangent of the average $\mathrm{Z}$ score was taken to obtain the average correlation coefficient [31].

Dependent measures were tested for differences between the three foot rotation conditions using a one-way, repeated measures analysis of variance (ANOVA) ( $\mathrm{p}<$ 0.05 ). For all omnibus test comparisons, the degrees of freedom used to calculate $p$ values were corrected using Greenhouse-Geisser sphericity estimates. Subsequently, pair-wise comparisons were used to assess differences between the NORM foot rotation condition and the INT and EXT foot rotation conditions, respectively. The alpha level for these comparisons was adjusted using a Sidak correction procedure, based on an a priori alpha level set at 0.05 . In addition, estimates of effect size (ES) were calculated following the guidelines of Dunlop et al [32].

The relationship between the foot rotation angle adopted during stance and PFM and IMP was also assessed using 
Pearson product moment correlation coefficient $(r)$. This was done in two ways: first, $r$ was calculated between the 'absolute' foot rotation angle in each condition and the corresponding PFM and IMP values obtained. Second, $r$ was calculated between the relative change in foot rotation angle in the INT and EXT foot rotation conditions and the corresponding change in PFM and IMP with respect to normal walking. This was done by subtracting the values recorded for each subject during the NORM walking condition from those obtained in the INT and EXT conditions.

Finally, differences in average gait speed and foot rotation angle in each of the three foot rotation conditions were assessed using a one way, repeated measures ANOVA and planned contrasts. The alpha level for these comparisons ( $\alpha=0.05)$ was adjusted using a Bonferonni correction procedure.

\section{Results}

Figure 2(a) and 2(b) depict the FM during normal walking and in the internal and external foot rotation conditions, respectively. In general, the FM in all three foot rotation conditions exhibits a biphasic shape whereby the FM initially resists inward rotation, then reverses just prior to mid stance to produce a positive FM that is indicative of resistance to outward rotation. Large inter-subject variability was present in the EXT foot rotation condition. Figure 3 shows that subjects could be characterized by one of two FM patterns, one similar in magnitude to that observed in the normal condition and another where the pattern demonstrated large excursions in magnitude during early and late stance. Evaluation of $r$ values calculated between pairs of FM curves indicate that on average, the FM patterns for the INT and NORM foot rotation conditions are more similar in magnitude and temporal characteristics $(r=0.79, \mathrm{RMSD}=49.9 \%)$ than the EXT and NORM foot rotation conditions $(r=0.69$, RMSD $=$ $147.6 \%)$.

Results of the ANOVAs performed on selected FM variables (table 2) reveal that PFM and IMP were significantly affected by foot rotation condition. Consequently, pairwise comparisons show differences in the NORM and EXT average PFM values $\left(2.8 \pm 0.8 \times 10^{-3}\right.$ vs. $6.7 \pm 4.1 \times 10^{-3}$, respectively, $\mathrm{p}<0.05, \mathrm{ES}=0.88$ ) and in the IMP values $\left(5.8 \pm 3.2 \times 10^{-2}\right.$ vs. $10.1 \pm 4.3 \times 10^{-2}$, respectively, $\mathrm{p}<0.05$, $\mathrm{ES}=0.92)$. Conversely, no differences were found between the NORM and INT conditions in ( $p>0.05$ for both PFM and IMP), nor was a significant main effect detected in OPFM across the three foot rotation conditions (INT $70 \pm 9 \%$, NORM $69 \pm 3 \%$, EXT $77 \pm 9 \%$, p > $0.05)$. Effects size values were relatively small for all of these latter comparisons (ES range $=-0.14-0.39$ ), except for differences between NORM vs. EXT OPFM, which exhibited a moderate ES of 0.51 .
The magnitudes of the relationships between the absolute foot rotation position and the magnitude of PFM and IMP were $r=0.39$ and $r=0.28$, respectively. Evaluation of the corresponding coefficient of determination values $\left(r^{2}\right)$ for these relationships suggest that very little of the variation seen in PFM or IMP may be explained by the absolute foot rotation angle adopted during stance $\left(r^{2}=0.15\right.$ and 0.08 respectively). When expressed relative to the values recorded for the normal walking condition, the magnitudes of the relationships of foot rotation position and PFM and IMP were $r=0.65$ and 0.31 , respectively. Once more, the portion of the variation in relative PFM and IMP explained by foot rotation position adopted relative to normal walking is comparatively small $\left(r^{2}=0.42\right.$ and 0.09 , respectively).

The average foot rotation angle adopted in each foot rotation position was found to be significantly different (INT $-9.1 \pm 7.9^{\circ}$, NORM $18.5 \pm 8.15^{\circ}$, EXT $40.2 \pm 8.7^{\circ}$, p < 0.016 for all planned contrasts), with all subjects walking during individual trials within 2.8 degrees of their average foot rotation angle in each of the conditions. Finally, no significant main effect was detected for average walking speeds (INT $1.08 \pm 0.16 \mathrm{~ms}^{-1}$, NORM $1.10 \pm 0.12 \mathrm{~ms}^{-1}$, EXT $\left.1.12 \pm 0.15 \mathrm{~ms}^{-1}, \mathrm{p}>0.05\right)$.

\section{Discussion}

The primary aim of this investigation was to assess whether time-history differences exist in the FM when modifying the foot rotation angle during walking. In addition, a description of the characteristics of the FM during normal walking was presented. With regards to differences in FM patterns across the three foot rotation condition, we assumed that during late stance, alignment of the foot with the direction of forward progress would necessitate a twisting action of the foot on the ground that would alter the FM pattern. Based on this, it was expected that internal and external foot rotation condition would alter the FM pattern in different directions. Specifically, for the internally rotated foot position, we contemplated that abduction of the foot would occur during late stance and subsequently produce a positive FM. Conversely, in the externally rotated foot condition, we expected the foot to adduct during late stance and subsequently produce a negative FM pattern. In the latter condition the FM timehistory is clearly altered, but not in the expected direction. There are several plausible explanations to the discrepancy between out hypothesis and the results obtained. The first explanation is that we did not consider that the FM reflects the sum of the force couples effects about a vertical axis [28]. As such, while the foot might be in fact attempting to align with the direction of forward progress during late stance, and consequently producing a negative $\mathrm{FM}$, the movements of other body segments acting to generate a larger coupling effect in the opposite direction ultimately produce a net FM that is not reflective of the 

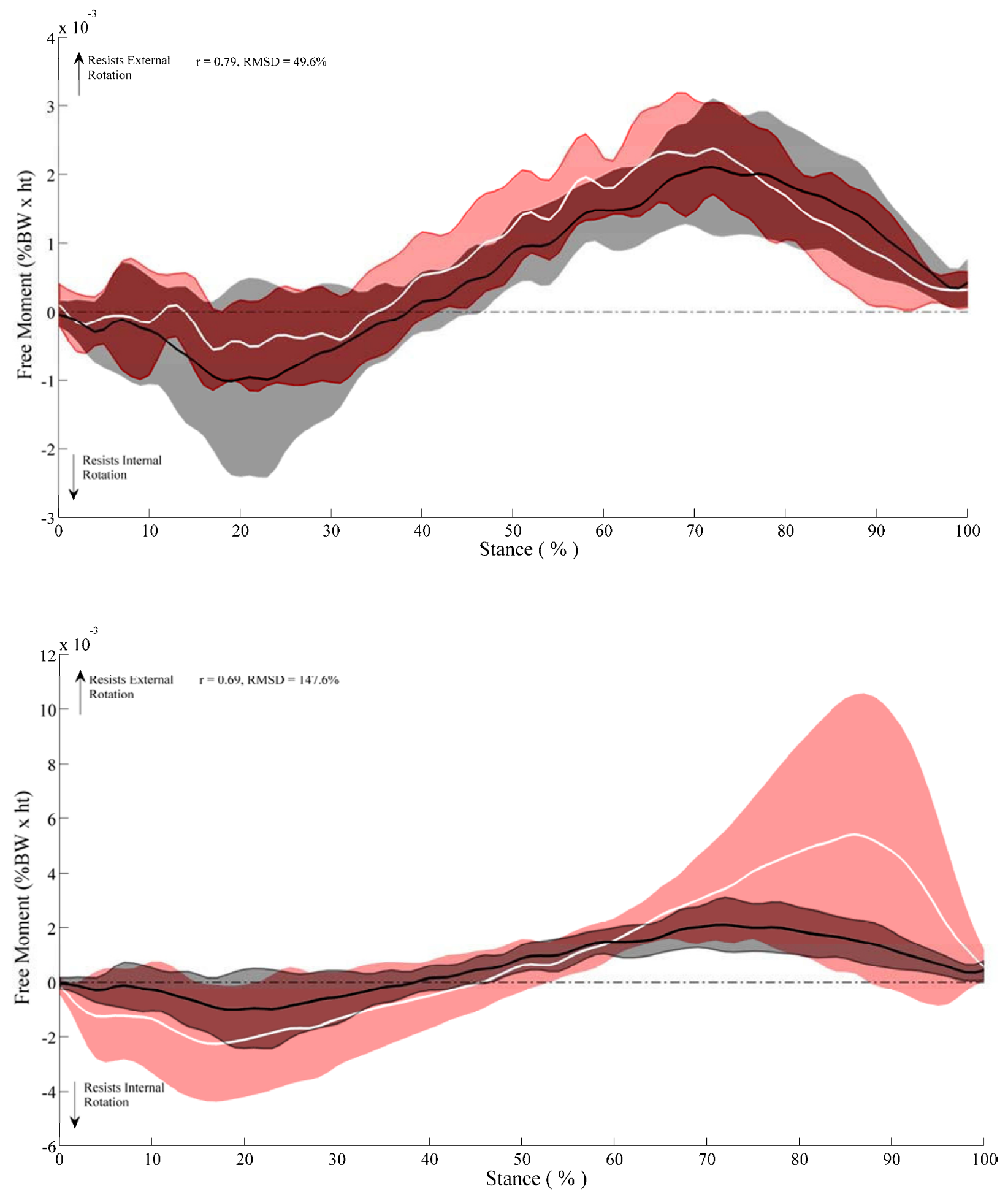

Figure 2

The free moment time history pattern normal walking. a) FM during normal walking (black line is average, grey shadows are \pm I SD variability bands) and when walking with an internally rotated foot (white line is mean, red shadows are \pm I SD variability bands) and b) FM during normal walking (black line is average, grey shadows are \pm I SD variability bands) and when walking with an externally rotated foot (white line is average, red shadows are \pm I SD variability bands). 


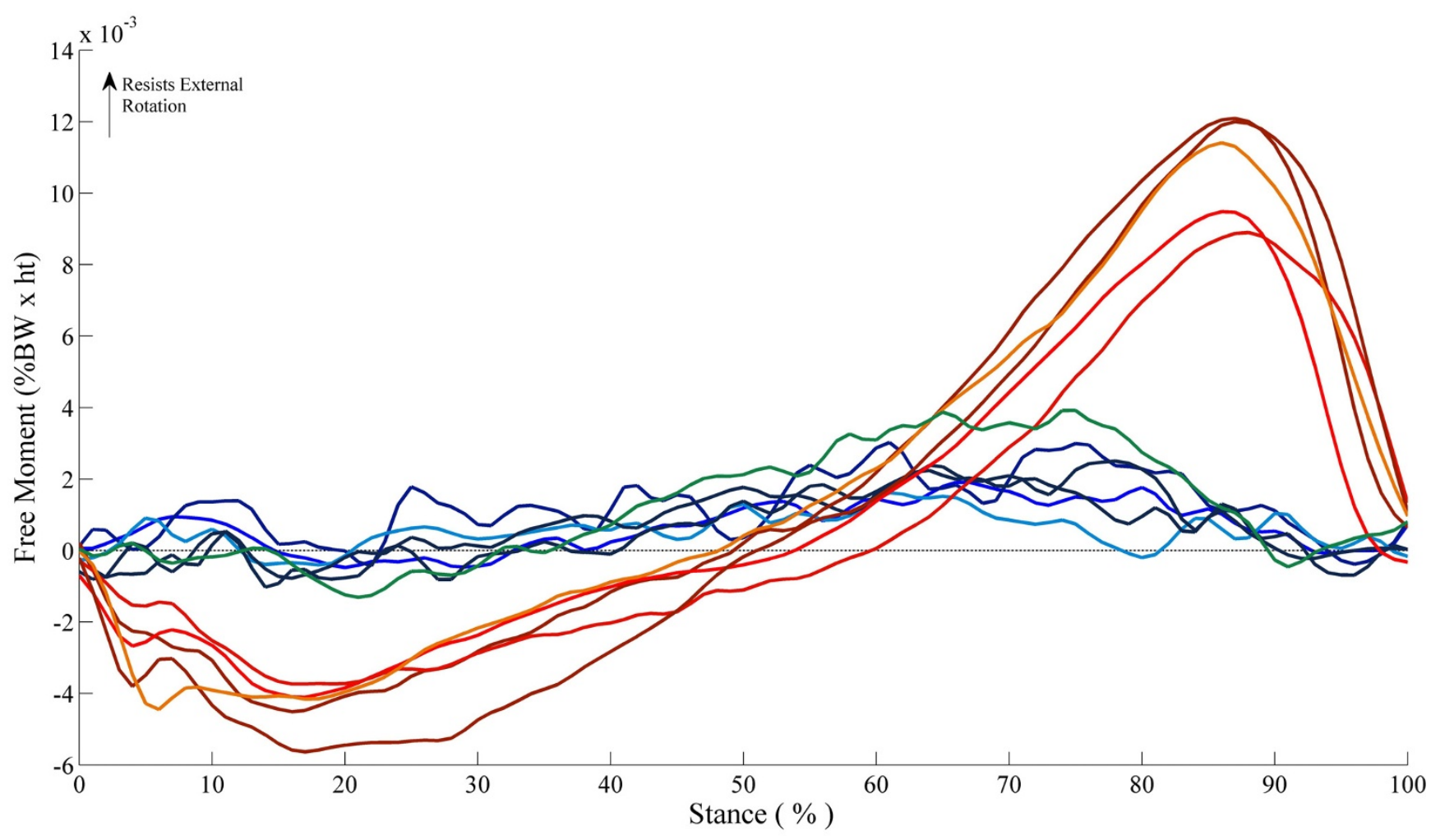

Figure 3

Individual subject free moment time history pattern during walking with an externally (EXT) rotated foot. Each line represents individual subject ensemble average curve of 5 trials in the external foot rotation walking condition.

movement of the foot. Another explanation relates to the argument presented by Li et al [13] as to the role of the FM during the double support phase of stance, where the FM produced by both feet acts in the same direction to counteract the moment produced by the horizontal forces about the body's vertical axis. Thus, a reversal of the FM pattern during late stance would likely create an imbalance about the body's vertical axis, which would be unbeneficial as this may interfere with the goal of forward progression [13].

Additionally, changes in the FM pattern during late stance were evident in the externally rotated foot condition. In this condition, several participants displayed normalized peak FM values that are as large as those reported for running in either healthy participants or those who have suf-

Table 2: Foot rotation angle, walking speed and FM measures in each of the three foot rotation conditions.

\begin{tabular}{|c|c|c|c|}
\hline \multirow[b]{2}{*}{ Variable } & \multicolumn{3}{|c|}{ Foot rotation condition } \\
\hline & Internal§ & Normal & Externalf \\
\hline Foot Rotation Angle (degrees) ${ }^{\dagger}$ & $-9.1 \pm 7.9$ & $18.5 \pm 8.15$ & $40.2 \pm 8.7$ \\
\hline Walking Speed $\left(\mathrm{ms}^{-1}\right)$ & $1.08 \pm 0.16$ & $1.10 \pm 0.12$ & $1.12 \pm 0.15$ \\
\hline Un-normalized Peak FM (Nm)* & $3.9 \pm 1.0$ & $3.4 \pm 1.4$ & $8.8 \pm 6.4$ \\
\hline PFM (dimensionless, $\times 10^{-3}$ ) & $3.2 \pm 0.9$ & $2.8 \pm 0.8$ & $6.7 \pm 4.1 \ddagger$ \\
\hline OPFM (\% stance) & $69 \pm 3$ & $70 \pm 9$ & $77 \pm 9$ \\
\hline $\operatorname{IMP}\left(\times 10^{-2}\right)$ & $7.5 \pm 2.7$ & $5.8 \pm 3.2$ & $11.0 \pm 4.1 \ddagger$ \\
\hline
\end{tabular}

$\mathrm{PFM}=$ normalized peak free moment, OPFM = occurrence of peak free moment, IMP = relative net impulse. All values presented as mean $\pm \mathrm{I} S \mathrm{SD}$.

* Un-normalized peak FM presented for the sake of comparison with results of other investigations.

† All foot rotation angles significantly different than each other $(p<0.016)$

$\ddagger$ Significantly different than normal walking condition $(p<0.05)$

$\S$ Effect size values for Norm vs. INT: PFM $=0.31$, OPFM $=-0.14, \mathrm{IMP}=0.39$.

$\notin$ Effect size values for Norm vs. Ext: PFM $=0.88$, OPFM $=0.51$, IMP $=0.92$. 
fered from tibial stress fractures [9,33]. The unnormalized peak FM values for these participants were as large as the average peak FM values reported by Nigg et al [34] for participants suffering from unilateral anterior cruciate ligament deficiency performing walking and running trials. Given that we standardized arm swing within subject and across conditions, the greater PFM values observed for some participants in the EXT condition suggests the existence of transverse plane movement modifications employed by other body segments. Unfortunately, we cannot identify what underlying movement modifications were made by those participants who exhibited greater FM values. However, it is interesting to note that changes in either absolute or relative PFM and IMP were not particularly dependent on the absolute or relative foot rotation angle adopted during stance. This may suggest that the greater FM values observed for some participants in the EXT condition may be related individual anatomical structural constraints, such as increased hip tightness, or perhaps due to asynchrony in subtalar and tibio-femoral rotations as a result of prolonged foot pronation [35].

We have mentioned in the introduction section that the FM may perhaps be reflective of the torsional loading experienced by the lower extremities during ambulation. However, this supposition may not hold true in light of the results presented and current knowledge on this topic. Specifically, Carter [12] found that torsional stresses during the push-off phase of walking are substantially greater than those recorded during running. If the FM is a proxy for torsional stresses than the PFM during the push-off phase in walking should be greater than that observed for running. Our results suggest that the PFM in walking is less than or equal to that for running, but not substantially greater. However, given the sensitivity of the FM to subject specific responses when asked to walk with an externally rotated foot, and inferring from the discussion of Milner et al [9], we contemplate that the FM may be indicative of individual gait characteristics that may predispose individuals to tibial stress fractures or other lower extremity injuries in which excessive transverse plane rotations are suspected to be part of the mechanism of injury [e.g. anterior knee pain]. As such, researchers in these topic areas might benefit from extracting the FM for purposes of differentiating between injured and non-injured participants, especially in prospective-type studies planning to utilize force plate data. In addition, the FM might be used for the evaluation of proposed interventional programs exploiting artificially-induced external foot rotation [e.g. $[19,20]]$.

There are some limitations to the present study. The first is that the changes in FM pattern and magnitude seen in subjects in the EXT condition may be primarily a result of foot placement targeting of the force plate. This has been previously found to have an insignificant effect on the magnitude and variability of most time domain orthogonal GRF parameters $[36,37]$, and since the FM is a function of these parameters we would expect similar results for the FM. The second limitation relates to the restriction of arm swing during walking. The standardization of arm swing was pertinent for comparisons across foot rotation conditions, as arm swing has been documented to affect the magnitude of the FM $[13,14]$. Whilst taking this into account, it should be noted that we employed an arm swing standardization procedure that is much less constraining then the ones employed by either $\mathrm{Li}$ et al [13] or Umberger [14]. However, future investigations are needed to establish whether changes in arm swing accompany changes in foot rotation position during walking, and subsequently how this affects the FM pattern.

\section{Conclusion}

This study presented a description of the time-history of the FM in normal walking and the effect of foot rotation upon it. On average, the free moment during walking tends to oppose inward rotation during early to just before mid stance at which time it reverses to oppose outward rotation. When walking with an internally rotated foot, selected FM indices were not statistically different than those recorded for normal walking. Conversely, when walking with an externally rotated foot, peak normalized free moment and impulse were significantly greater than normal walking.

This study is one of less than a handful of investigations that has reported upon the FM during walking. Future research directions on the behaviour of the FM waveform in other walking conditions, and in different subject populations, would help facilitate our understanding of the FM as an objective gait assessment measure.

\section{Competing interests}

The authors declare that they have no competing interests.

\section{Authors' contributions}

SA conceived the study, and was responsible for data analysis, statistical analysis, and drafting of the manuscript. TA designed the experimental protocol, collected all data, and helped draft the manuscript. PAC was senior author, providing guidance and advice on all aspects of the study and, in addition, was responsible for the development of the software used for data analysis. All authors read and approved the final manuscript.

\section{References}

I. Birrell SA, Hooper RH, Haslam RA: effect of military load carriage on ground reaction forces. Gait and Posture 2007, 26:6||-6|4.

2. Chao EY, Laughman RK, Schneider E, Stauffer RN: Normative data of knee joint motion and ground reaction forces in adult level walking. J Biomech 1983, 16:219-233. 
3. Gottschall JS, Kram R: Ground reaction forces during downhill and uphill running. J Biomech 2005, 38:445-452.

4. Levinger $P$, Gilleard W: Tibia and rearfoot motion and ground reaction forces in subjects with patellofemoral pain syndrome during walking. Gait and Posture 2007, 25:2-8.

5. Nilsson J, Thorsensson A: Ground reaction forces at different speeds of human walking and running. Acta Physiol Scand 1989 , 136:217-227.

6. Stacoff A, Diezi C, Luder G, Stüssi E, Kramers-de Quervain IA Ground reaction forces on stairs: effects of stair inclination. Gait and Posture 2005, 21 1:24-38.

7. Nigg BM: Experimental techniques used in running shoe research. In Biomechanics of Running Shoes Edited by: Nigg BM. Champagne, IL, USA, Human Kinetics; | 986:27-6I.

8. Holden JP, Cavanagh PR: The free moment of ground reaction in distance running and its changes with pronation. J Biomech 1991, 24:887-897.

9. Milner CE, Davis IS, Hamill J: Free moment as a predictor of tibial stress fractures. J Biomech 2006, 39:2819-2825.

10. George WT, Vashishth D: Influence of phase angle between axial and torsional loadings on fatigue fractures of bone. J Biomech 2005, 38:819-825.

II. Vashishth D, Tanner KE, Bonfield W: Fatigue of cortical bone under combined axial-torsional loading. J Orthop Res 200I, 19:414-420.

12. Carter DR: Anisotropic analysis of strain rosette information from cortical bone. J Biomech 1978, I I:199-202.

13. $\mathrm{Li} \mathrm{Y}$, Wang $\mathrm{W}$, Crompton RH, Gunther MM: Free vertical moments and transverse forces in human walking and their role in relationship to arm swing. J Exp Biol 200I, 204:47-58.

14. Umberger BR: Effects of suppressing arm swing on kinematic, kinetics and energetic of human walking. J Biomech 2008, 4I:2575-2580.

15. Eredmir A, Piazza SJ: Rotational foot placement specifies the lever arm of the ground reaction force during the push-off phase of walking initiation. Gait and Posture 2002, I 5:2 | 2-2 I9.

16. Fuchs R, Staheli LT: Sprinting and intoeing. J Pediatr Orthop 1996 |6:489-49|.

17. Bojsen-Møller F: The human foot a two speed construction. In Biomechanics V Edited by: Asmussen E, Jorgensen K. Baltimore, MD, USA, University Park Press; 1978:261-266.

18. Andrews M, Noyes FR, Hewett TE, Andriacchi TP: Lower limb alignment and foot angle are related to stance phase knee adduction in normal subjects: a critical analysis of the reliability of gait analysis data. J Orthop Res 1996, I 4:289-295.

19. Lynn SK, Costigan PA: Effect of foot rotation on knee kinetics and hamstring activation in older adults with and without signs of knee osteoarthritis. Clin Biomech (Bristol, Avon) 2008, 23:779-786

20. Teichtahl AJ, Morris ME, Wluka AE, Baker R, Wolfe R, Davis SR, Cicuttini FM: Foot rotation a potential target to modify the knee adduction moment. J Sci Med Sports 2006, 9:67-71.

21. Wang JW, Kuo KN, Andriacchi TP, Galante JO: The influence of walking mechanics and time on the results of proximal tibial osteotomy. J Bone Joint Surg Am 1990, 72:905-909.

22. Lynn SK, Kajaks T, Costigan P. The effect of internal and external foot rotation on the adduction moment and lateral-medial shear forces at the knee during gait. J Sci Med Sport 2008 I I:444-45I.

23. Costigan PA, Wyss UP, Deluzio KJ, Li J: Semiautomatic 3-dimensional knee motion assessment system. Med Biol Eng Comput 1992, 30:343-350.

24. Deluzio KJ, Wyss UP, Li JA, Costigan PA: A procedure to validate 3-dimensional motion assessment systems. J Biomech 1993, 26:753-759.

25. Li J, Wyss UP, Costigan PA, Deluzio KJ: An integrated procedure to assess knee-joint kinematics and kinetics during gait using an optoelectric system and standardized X-rays. J Biomed Eng 1993, 1 5:392-400.

26. AMTI model OR6-5 biomechanics platform instruction manual [http://www.biomch-l.org]. AMTI Inc., Watertown, MA, USA. Available via Biomech-L listserve

27. AMTI force platform calculations [http://www.biomch-l.org] AMTI Inc., Watertown, MA, USA. Available via Biomech-L listserver

28. Kwon YH: Force Plate Issues. [http://www.kwon3d.com/theory/ grf/cop.html].
29. Hamill J, Bates BT, Knutzen KM, Sawhill JA: Variations in ground reaction force parameters at different running speeds. Hum Mov Sci 1983, 2:47-56.

30. Derrick TR, Bates BT, Dufek JS: Comparative evaluation of timeseries data sets using the Pearson product-moment correlation coefficient. Med Sci Sports Exerc 1994, 26:919-928.

31. Derrick TR, Thomas JM: Time series analysis: The cross correlation function. In Innovative Analysis of Human Movement Edited by: Stergiou N. Champaign, IL: Human Kinetics; 2004:189-205.

32. Dunlop WP, Cortina JM, Vaslow JB, Burke MJ: Meta-analysis of experiments with matched groups or repeated measures designs. Psychological Methods 1996, I: 170-177.

33. Creaby MW, Dixon SJ: External frontal plane loads may be associated with tibial stress fractures. Med Sci Sports Exerc 2008, 40:1669-1674.

34. Nigg BM, Bell GD, Kiefer GN, Luethi SM, Schachar NS: A quantitative assessment of asymmetry of locomotion parameters in subjects with chronic anterior cruciate ligament injuries. In Proceedings of the second biannual conference of the Canadian society of biomechanics. I 3 September 1982 Edited by: Reid JG, Bryant T, Olney S, Smith B, Stevenson J, Walmsley R. Kingston, ON; 1982:9-II.

35. Moss RI, Devita P, Dawson ML: biomechanical analysis of patellofemoral stress syndrome. J Athl Train 1992, 27:64-9.

36. Grabiner MD, Feuerbach JW, Lundin TM, Davis BL: Visual guidance does not influence ground reaction force variability. J Biomech 1995, 28: $1115-1117$

37. Wearing SC, Urry SR, Smeathers JE: The effect of visual targeting on ground reaction force and temporospatial parameters of gait. Clin Biomech (Bristol, Avon) 2000, 15:583-591.

Publish with Biomed Central and every scientist can read your work free of charge

"BioMed Central will be the most significant development for disseminating the results of biomedical research in our lifetime. "

Sir Paul Nurse, Cancer Research UK

Your research papers will be:

- available free of charge to the entire biomedical community

- peer reviewed and published immediately upon acceptance

- cited in PubMed and archived on PubMed Central

- yours - you keep the copyright 